\title{
Crowdfunding: Motives, Definitions, Typology and Ethical Challenges
}

\author{
${ }^{1}$ Department of Industrial Engineering Management, Institute of Strategy and Venturing, Aalto University, Maarintie 8, 02150 \\ Espoo, Finland, E-mail: mokter.hossain@aalto.fi. http://orcid.org/0000-0003-4156-6206. \\ ${ }^{2}$ Department of Management and Entrepreneurship, Turku School of Economics, University of Turku, Rehtorinpellonkatu 3 , \\ 20500 Turku, Finland, E-mail: gospel.o.oparaocha@utu.fi
}

\begin{abstract}
:
Crowdfunding is an emerging phenomenon that has attracted significant interest from scholars and practitioners alike, mainly due to its appeal as an alternative source of funding. As crowdfunding has grown exponentially, so have the associated challenges and opportunities. In this conceptual paper, we define crowdfunding; discuss its characteristics, related terminologies, key elements and ethical issues. We also propose a typology for crowdfunding and indicate various issues associated with it. The final section includes the implications of this study and suggestions for future research. This paper aims to inspire a scholarly debate and further develop the theoretical foundation of the crowdfunding literature. This may also prompt practitioners to take note of the emerging concerns as the crowdfunding phenomenon is transforming from a marginal to a mainstream discipline.
\end{abstract}

Keywords: crowdfunding, motivation, typology of crowdfunding, ethics, entrepreneurial finance DOI: 10.1515/erj-2015-0045

\section{Introduction}

For centuries, attracting outside capital to finance a project or entrepreneurial initiative has mostly depended on the conventional fund providers, such as banks, venture capitalists, government agencies, and foundations (Cowling et al. 2015; Xiang, Worthington, and Higgs 2014). Crowdfunding has emerged as an increasingly popular and viable alternative way of funding a variety of initiatives (Belleflamme, Lambert, and Schwienbacher 2013; Fraser, Bhaumik, and Wright 2015; Rechtman and O'Callaghan 2014; Schwienbacher and Larralde 2012). Recently, a vast array of crowdfunding initiatives have successfully received financial backing by directly soliciting private individuals to each pledge, donate, or lend a small sum of money (e. g., Hollas 2013).

Crowdfunding has attracted media coverage and attention from academia, as well as from the traditional stakeholders around the world. There are several types of crowdfunding in practice, namely donation-based, equity-based, lending-based and reward-based crowdfunding (Massolution 2012). Crowdfunding derives from the concept of crowdsourcing (Howe 2006), and it is sometimes even considered as a sub-branch of crowdsourcing due to the characteristics shared with other crowd-based initiatives (Hossain 2015). Some scholars, however, argue that crowdfunding is best understood as a standalone concept (Brabham 2013), so there is an obvious need to distinguish crowdfunding from other crowd-based concepts. In this paper, we start the process of separating crowdfunding from crowdsourcing and other crowd-based initiatives by discussing in detail the distinctive characteristics of crowdfunding, thus laying the foundation for scholars to approach crowdfunding as a fledgling discipline in its own right.

As a novel fundraising method, crowdfunding is radically different from the alternatives to finance startups. Hence, a theoretical foundation for crowdfunding phenomenon is essential. The extant literature lacks a cohesive theoretical foundation. Understanding various elements and characteristics of crowdfunding is necessary. Crowdfunding campaigns raise some ethical concerns, such as exposure to fraudulent campaigns, lack of privacy, and abuse of the raised funding (Snyder, Mathers, and Crooks 2016). Crowdfunding has become an additional source of funding for research projects where lack of peer reviewing and capacity to manipulate the fund through empty promises are common practices (Blanchard and Sabuncu 2016).

Despite all the buzz around this nascent phenomenon, as Mollick (2014) argues, "even basic academic knowledge of the dynamics of crowdfunding is lacking" (p. 1). Many opportunities and challenges are also emerging for crowdfunding (Burtch, Ghose, and Wattal 2013). Therefore, as Jones, Coviello, and Tang (2011) suggest for a young discipline, "an awareness of the inconsistencies, issues and nature of the phenomena under 
study, as well as the surrounding interim debates are fundamental for the development of theory and paradigmatic unity" (p. 632).

This paper aims to provide a basic conceptual understanding of the characteristics of crowdfunding, its typologies, and the ethical issues involved. It contributes to establishing a basic conceptual foundation for the crowdfunding phenomenon within the entrepreneurial finance discipline. In other words, we aim to fill the gap in the existing literature that scholars have pointed out (see Mollick 2014). This is crucial for theory development, as the existing literature emphasizes that in the absence of a unifying conceptual foundation, a given scholarly domain risks being amorphous, thus hindering both theory building and the further development of the discipline (e. g., Keupp and Gassmann 2009; Jones, Coviello, and Tang 2011).

The remainder of this paper is structured as follows. In the following section, we review the various definitions for crowdfunding that are present in the existing literature and show how diverse the definitions of crowdfunding are. We then propose a comprehensive definition of crowdfunding. In the next section, we discuss the characteristics of crowdfunding as a phenomenon. Next, we provide a typology for crowdfunding and its common terminology followed by a section that discusses the important elements of crowdfunding. Subsequently, a comprehensive discussion on the ethics of crowdfunding has been presented. In the final section, we point out the implications and avenues for future research.

\section{What is Crowdfunding?}

The popularity of crowdfunding has led to a wide variety of definitions being proposed. However, despite the increasing scholarly interest in crowdfunding, no clear definition fully captures the dynamics of this phenomenon. Table 1 presents 17 existing definitions for crowdfunding. Our intention here is not to encompass all their various elements but rather to provide a concise definition that integrates all the key elements of the crowdfunding phenomenon. It should be noted that due to there being few published academic articles on crowdfunding, we also explored business magazines, working papers, and books. We will now elaborate on these existing definitions.

Steinberg, DeMaria, and Kimmich (2012) define crowdfunding as an emphasis on public donation to gain capital for new ventures. His definition does not consider many aspects, however, including the role of the Internet. The definition of Rubinton (2011) also does not cover the importance of social media and the Internet. Wicks (2013) emphasizes equity along with donation and reward, but the importance of the Internet and social networking are again absent from the definition. In the same vein, Massolution (2012) ignores the roles of both the Internet and social networking, as well as reward-based types of crowdfunding, such as pre-purchasing. Harrington (2014), in contrast, does consider the role of the Internet in his definition, but the typical purpose of fundraising via crowdfunding is unclear. Hemer (2011)'s definition considers it as donation in exchange for a reward, but it does not cover other high-risk forms of crowdfunding, such as equity crowdfunding.

The definition of Belleflamme, Lambert, and Schwienbacher (2013) also fails to consider some aspects, such as peer-to-peer lending and fundraising by individuals or groups in areas, such as music. The definition of Hemer (2011) also does not cover peer-to-peer lending and aspects of social capital. Mollick (2014), meanwhile, tries to avoid the same pitfall by providing a definition that includes some additional elements of the crowdfunding phenomenon. De Buysere et al. (2012) also attempted to come up with a broader definition, but the role of social networks lacks emphasis, despite it being a crucial part of the whole crowdfunding process. What is more, their definition is constrained to an entrepreneurial perspective, while the true scope of crowdfunding goes far beyond this. They also ignore some conspicuous elements, such as peer-to-peer lending. Lebraty and Lobre-Lebraty (2013) provide a simple definition, but it does not articulate several fundamental elements of crowdfunding. Belt, Brummer, and Gorfine (2012) consider most elements of crowdfunding, although the expectation of funders is missing. In contrast to many of the other attempts, the definitions of Ingram and Teigland (2013) and Marom and Sade (2014) both attribute due importance to social networking.

Table 1: Definitions of crowdfunding in the literature.

\begin{tabular}{ll}
\hline Source & Definition \\
\hline Belleflamme, Lambert, and Schwienbacher (2013) & "Crowdfunding involves an open call, mostly through the \\
& $\begin{array}{l}\text { Internet, for the provision of financial resources either in } \\
\text { the form of donation or in exchange for the future } \\
\text { product or some form of reward to support initiatives for } \\
\text { specific purposes." }\end{array}$
\end{tabular}


Belt, Brummer, and Gorfine (2012)

De Buysere et al. (2012)

Harrington (2014)

Hemer (2011)

Ideavibes (2011)

Ingram and Teigland (2013)

Lebraty and Lobre-Lebraty (2013)

Marom and Sade (2014)

Massolution (2012)

McMillan Web-Dictionary (2014)

Mollick (2014)

Oxford Dictionary (2014)

Rubinton (2011)

Steinberg (2012) "process by which capital is raised for a project, initiative or enterprise through the pooling of numerous or relatively small financial contributions or investments, via the internet."

"Crowdfunding can be defined as a collective effort of many individuals who network and pool their resources to support efforts initiated by other people or organizations. This is usually done via or with the help of the Internet. Individual projects and businesses are financed with small contributions from a large number of individuals, allowing innovators, entrepreneurs and business owners to utilize their social networks to raise capital."

"Crowdfunding is simply the collective effort of individuals who network and pool their money, usually via the Internet, to support efforts initiated by other people or organizations."

"open call, essentially through the Internet, for the provision of financial resources either in form of donations (without rewards) or in exchange for some form of reward and/or voting rights in order to support initiatives for specific purposes."

"Crowdfunding is raising funds online through the collective wisdom of individuals or groups of people, collectively referred to as: the crowd."

"The accumulation of small investments in individual projects by a large number of individuals (the 'crowd') via or with the help of the Internet and social networks, allows an entrepreneur to pitch an idea or business plan to more than just family and friends."

"Crowdfunding can be defined as a resource allowing a project initiator to obtain financing from Internet users." "Crowdfunding is an innovative funding mechanism which leverages the internet and social networks in order to raise funds from a large number of investors, usually raising small amounts from each investor."

"Financial contributions from online investors, sponsors or donors to fund for-profit or non-profit initiatives or enterprises. Crowdfunding is an approach to raising capital for new projects and businesses by soliciting contributions from a large number of stakeholders following three types of crowdfunding models: (1) Donations, Philanthropy and Sponsorship where there is no expected financial return, (2) lending and (3) investment in exchange for equity, profit or revenue sharing."

"The use of the web or another online tool to get a group of people to finance a particular project."

"The efforts by entrepreneurial individuals and groups cultural, social, and for-profit - to fund their ventures by drawing on relatively small contributions from a

relatively large number of individuals using the internet, without standard financial intermediaries."

"The practice of funding a project or venture by raising many small amounts of money from a large number of people, typically via the Internet."

"The process of one party progressing towards a goal by requesting and receiving small contributions from many parties in exchange for a form of value to those parties." "Crowdfunding is the process of asking the general public for donations that provide startup capital for new ventures." 
Wicks (2013)

"Crowdfunding is where a large number of people (a crowd) financially support a project by giving a relatively small amount of money either in return for a reward, as a donation, or potentially in return for equity."

Wikipedia (2014) "The collective cooperation, attention and trust by people who network and pool their money together, usually via the Internet, in order to support efforts initiated by other people or organizations."

It is clearly difficult to grasp what crowdfunding really means, because each definition (see Table 1) has one or more key missing elements. The fundamental idea behind crowdfunding is as follows: The initiator demonstrates his or her idea in the best possible manner within the resource, time, and other constraints. A demonstration is presented primarily via the Internet, and this may include written documents and audio/video media, so potential funders can understand the initiator's idea to the best of their abilities. This idea should be appealing enough to convince funders to pledge funds. To disseminate the idea, the founders may use an intermediary crowdfunding platform (a common practice) or their own platform (which is less common) for demonstration purposes. The open call for funding is then mainly promoted through social media (e. g., Facebook, MySpace, Twitter, YouTube, LinkedIn, Reddit, Google+, Quora, and Chinese Sina Weibo), as well as through other Internet-based communication (e. g., email). An inspiring and easily understandable message is crucial to attract a large number of funders. The timeframe for a fundraising campaign is typically between 30 and 45 days. The total amount pledged by funders is usually displayed in real time on the crowdfunding platform. Intermediary platforms take commissions ranging from 8 to 10 percent from projects that successfully raise funds, including transaction handling costs from payment processors like Amazon and PayPal. By integrating all the above-mentioned elements, we propose the following definition:

Crowdfunding is an Internet-based funding method for the realization of an initiative through online distributed contributions and micro-sponsorships in the form of pledges of small monetary amounts by a large pool of people within a limited timeframe. It is the financing of a task, idea, or project by making an open call for funding, mainly through Web 2.0 technologies, so funders can donate, pre-purchase the product, lend, or invest based on their belief in an appeal, the promise of its founder, and/or the expectation of a return.

\section{Characteristics of Crowdfunding}

Following the definition presented above, we will now discuss the characteristics of crowdfunding. Over the last decade, it has filled a significant portion of the gap in venture finance (Burtch, Ghose, and Wattal 2015). In the early stages of crowdfunding, it was predominantly used to fund artistic and other creative endeavors. It later emerged as a means of raising capital to support innovations, entrepreneurial ideas, and ventures (Schwienbacher and Larralde 2010). Some fundamental elements distinguish crowdfunding from the traditional investors, such as banks and venture capitalists, making it a novel source of funding. Firstly, funding for start-ups is very scarce, so crowdfunding helps fill the gap in the early stage of financing. Secondly, crowdfunding harnesses the influential power of the Internet, particularly through social media. Thirdly, it is a novel marketing channel. Fourthly, it encourages unique ideas to be tested by the public and ultimately realized. Finally, it facilitates direct engagement with consumers (Younkin and Kashkooli 2016).

We argue that the core characteristics of crowdfunding highlighted above are among the key features that distinguish it from traditional financing methods (cf. Pichler and Tezza 2016. We will now elaborate further on these differences and return to discussing these characteristics in more details in the different parts of this paper. This should provide a more insightful overview of crowdfunding as an intriguing alternative approach to entrepreneurial finance when compared to the traditional offline funding sources.

It is well known that many new entrepreneurs face difficulties in raising the funds needed to actualize their ideas through traditional fund providers, such as banks and venture capitalists. The crowdfunding approach, therefore, presents a different and attractive option for these entrepreneurs (Burtch, Ghose, and Wattal 2015). Crowdfunding also aids entrepreneurs in gaining the wide exposure that will eventually help them to raise further funding (Agrawal, Catalini, and Goldfarb 2015). According to Assenova et al. (2016), something that crowdfunding offers, and which is lacking from traditional funding, is that it creates multiple layers of return, thus creating a community. In other words, crowdfunding investors are getting more than just a financial return on their investments. We will elaborate on this further when we discuss the motives and incentives of participating in crowdfunding. 
According to the 2015CF Crowdfunding Industry Report, the industry was expected to raise $\$ 34.4$ billion in funding during 2015, double that of 2014 and a five-fold increase on 2013. The report found that peer-topeer landing enjoyed the greatest share of monetary value. Interestingly, in 2014, the growth of crowdfunding jumped by 320 percent to $\$ 3.4$ billion in Asia, exceeding the figure for Europe ( $\$ 3.26$ billion). An individual's investment in a crowdfunding project typically ranges from $\$ 1$ to $\$ 100$, but huge investments from a single donor are also seen. For example, the largest individual investment of $\$ 100,000$ was witnessed by the equitybased platform Crowdcube in the UK (see Macht and Weatherston 2014). The most popular crowdfunding initiatives fall into the business and entrepreneurship category, followed by social causes, entertainment and performance arts, and real estate (Agrawal, Catalini, and Goldfarb 2015). Crowdfunding platforms, such as KickStarter, IndieGoGo, RocketHub, and GoFundMe are all facilitating the growing number of transactions. In addition, crowdfunding platforms like Kiva.org and Prosper.com are facilitating new ways of microfinancing in the area of peer-to-peer lending (Zhang and Liu 2012).

Crowdfunding differs from other crowd-based concepts, such as crowdsourcing, open-source software development, open-innovation movements. These community-based concepts are all built upon the notion of tapping into the power/wisdom of the crowd. In contrast, crowdfunding usually entails monetary contributions from a community of backers. For instance, Gerber and Hui (2013) found that the primary motivation for founders to engage in crowdfunding is to raise funds, because it provides an easy-to-use and organized platform where distributed financial contributions can be solicited and collected from many people, therefore allowing nascent entrepreneurs to sidestep the conventional business financiers (Mollick 2014). Other crowd-based concepts usually involve participatory and intellectual inputs other than a monetary contribution (cf. Bannerman 2013; Brabham 2013).

As a discipline, crowdfunding stands at the juncture of business ventures, economics, finance, information systems, journalism, management, law, and sociology (Agrawal, Catalini, and Goldfarb 2015; Aitamurto 2011; Bradford 2012; Burtch, Ghose, and Wattal 2013; Mollick 2014; Schwienbacher and Larralde 2012). Consequently, a variety of discussions and research protocols are being developed, and several published academic articles have attracted enormous attention in recent years (e. g., Belleflamme, Lambert, and Schwienbacher 2014; Mollick 2014). In addition, some journals have published special issues on crowdfunding, such as Venture Capital in 2013 and Strategic Change, New Media \& Society, and Entrepreneurship Theory and Practice in 2015. This shows the growing importance of the crowdfunding domain among scholars, practitioners, and policy makers.

\section{Common Terminology and a Typology for Crowdfunding}

\section{Common Terminology}

Table 2 explains some common terms associated with crowdfunding, so readers can recognize the key parties involved in crowdfunding activities.

Table 2: Common terms used in crowdfunding literature.

\begin{tabular}{|c|c|}
\hline Term & Explanation \\
\hline Founder & $\begin{array}{l}\text { This is the person, team, or organization initiating the } \\
\text { fundraising campaign on a crowdfunding platform for a } \\
\text { particular purpose. The founder is also referred to by } \\
\text { various other names, such as initiator, receiver, project } \\
\text { team/group, etc }\end{array}$ \\
\hline Funder & $\begin{array}{l}\text { This individual pledges to financially support a } \\
\text { crowdfunded initiative. Funders may expect to receive no } \\
\text { tangible return, a product, a return on their investment } \\
\text { with interest, or equity ownership. Based on an } \\
\text { individual project's commitment, a funder may also be } \\
\text { referred to as a donor, backer, lender, investor, } \\
\text { pre-purchase customer, etc }\end{array}$ \\
\hline Crowdfunding platform & $\begin{array}{l}\text { This is the Internet-based platform being used as the } \\
\text { portal to showcase a campaign idea and the associated } \\
\text { information, such as a detailed project description, } \\
\text { pictures, audio and video, pledging options, length of the } \\
\text { project, details of the founder, etc }\end{array}$ \\
\hline
\end{tabular}


Campaign

Investment threshold
This is an open call to financially back a project or idea during a specified timeframe. Important elements in a campaign include the project description and efficient interaction, such as by responding to enquiries and concerns, providing updates, and integrating feedback. A campaign typically lasts for 30-45 days.

The investment threshold determines the success or failure of a crowdfunding campaign. The most popular option is the All-or-Nothing (AON) model, where all funds are returned to the funders if the stated campaign target is not met. The Keep-it-All (KIA) model, meanwhile, give the founder access to the pledged funds, even when the target amount is not met.

\section{A Typology for Crowdfunding}

Crowdfunding can be broadly classified into two groups, commercial and philanthropic, although a project sometimes falls into both groups. In commercial initiatives, funders expect some kind of return on their investment, while funders do not expect any personal return from philanthropic projects, because they love being part of a greater cause. In the same vein, Hemer (2011) specifies a further type (called intermediate) that falls between the commercial and philanthropic types. He argues that the future commercial success of some projects is unclear. For example, projects, such as Skype, Facebook, and YouTube would have fallen into this type during their very early stages. Lambert and Schwienbacher (2010), meanwhile, classify crowdfunding into three groups based on the nature of the reward: donation, active investment, and passive investment. Wojciechowski (2009) classifies crowdfunding into social lending and micro-funding. Hemer (2011) also identifies five types of crowdfunding: threshold pledge, micro-lending, investment, holding, and club. In contrast, Bradford (2012) and Griffin (2013) found five distinct categories of crowdfunding based on the return that funders expect to receive on their investment: (1) the donation model, (2) the reward model, (3) the pre-purchase model, (4) the lending model, and (5) the equity model. Crowdfunding for journalism is mostly neglected by the crowdfunding literature. When we consider the commitment between the founder and funders, crowdfunding can also be broadly categorized into four types: donation-based, reward-based, lending-based, and equity-based models. In Table 3, we present a proposed typology to identify the similarities and differences among the various types of crowdfunding.

Table 3: A proposed typology for crowdfunding.

\begin{tabular}{|c|c|c|c|c|}
\hline Type & $\begin{array}{l}\text { Donation-based } \\
\text { crowdfunding }\end{array}$ & $\begin{array}{l}\text { Reward-based } \\
\text { crowdfunding }\end{array}$ & $\begin{array}{l}\text { Equity-based } \\
\text { crowdfunding }\end{array}$ & $\begin{array}{l}\text { Lending-based } \\
\text { crowdfunding }\end{array}$ \\
\hline $\begin{array}{l}\text { Motivation of } \\
\text { funder }\end{array}$ & Intrinsic and social & $\begin{array}{l}\text { Intrinsic, social and } \\
\text { extrinsic }\end{array}$ & Financial gain & $\begin{array}{l}\text { Social and/or } \\
\text { financial }\end{array}$ \\
\hline Type of contribution & Donation & Pre-order & Investment & Loan \\
\hline $\begin{array}{l}\text { Expected return of } \\
\text { funder }\end{array}$ & Intangible benefits & $\begin{array}{l}\text { Tangible and } \\
\text { intangible benefits }\end{array}$ & $\begin{array}{l}\text { Return on } \\
\text { investment }\end{array}$ & $\begin{array}{l}\text { Return on } \\
\text { investment }\end{array}$ \\
\hline $\begin{array}{l}\text { Motivation of } \\
\text { funder }\end{array}$ & Intrinsic and social & $\begin{array}{l}\text { Intrinsic, social and } \\
\text { extrinsic }\end{array}$ & Financial gain & $\begin{array}{l}\text { Social and/or } \\
\text { financial }\end{array}$ \\
\hline Main focus & $\begin{array}{l}\text { Journalism/worthy } \\
\text { cause/philanthropy }\end{array}$ & $\begin{array}{l}\text { Products for early } \\
\text { adopters/gifts }\end{array}$ & Start-ups & Short-term borrower \\
\hline $\begin{array}{l}\text { Complexity of } \\
\text { process }\end{array}$ & Very low & Low & High & Medium \\
\hline $\begin{array}{l}\text { Example primary } \\
\text { beneficiaries }\end{array}$ & $\begin{array}{l}\text { Project owner(s), } \\
\text { musicians, } \\
\text { non-profit entities }\end{array}$ & Start-ups, funders & Start-ups & $\begin{array}{l}\text { Individuals, business } \\
\text { entities }\end{array}$ \\
\hline Type of contract & $\begin{array}{l}\text { A contract without } \\
\text { existential reward }\end{array}$ & Purchase contract & $\begin{array}{l}\text { Shareholding } \\
\text { contract }\end{array}$ & Lending contract \\
\hline
\end{tabular}

Donation-based crowdfunding is the simplest and most popular type of crowdfunding. In this model, funders donate for philanthropic purposes. These donations are usually made to social and charitable initiatives, with funders not expecting a return on their investment (Mollick 2014). Donations can also be made to profit-oriented enterprises, but pure-donation platforms are uncommon and generally focus on requests from charities and 
nonprofit organizations (Bradford 2012). Funders generally donate to a cause they believe in, such as raising money to enable a music band to go on tour (De Buysere et al. 2012). These funders may receive some symbolic return, such as a message of gratitude from the founders, but there is no material reward. The donation-based model is not limited to nonprofit organizations, however, because some people may donate to an initiative if it will enable them to later purchase a desirable product on the open market (Belleflamme, Lambert, and Schwienbacher 2013). Naturally, the risk associated with donation-based crowdfunding is very low, because there is no obligation for founders to provide a return, nor do the funders expect one.

Reward-based crowdfunding provides funders with a non-monetary return, such as one of the first manufactured products. In this model, entrepreneurs invite potential customers to pre-order their product offering, sometimes at a lower-than-usual price. Founders may also offer gifts and other non-monetary rewards to their funders, but they never pay interest or a share of their business earnings (Bradford 2012). In the light of our review of the ethical dilemmas and real-life incidents that have occurred so far, it seems there is a medium level of risk for both the founder and funders (see Hauge and Chimahusky 2016). In the worst-case scenario, a founder may be unable to manufacture the proposed product for some reason, so the funders will not receive their expected reward. In general, people with early adopter traits tend to become funders in this type of crowdfunding.

Equity-based crowdfunding is a model whereby funders expect a financial return on their investment. It is also referred as a profit-sharing model. In this model, entrepreneurs urge people to invest money in order to receive a share of the venture's future earnings (Belleflamme, Lambert, and Schwienbacher 2013). Equity crowdfunding entails a great deal of business and legal consideration from both intermediary crowdfunding organizations and investors, as it clearly falls into the area of selling securities. Crowdcube, Seedrs, and IPOVillage are some popular equity-based crowdfunding platforms. In the USA, for instance, laws for equity-based crowdfunding are being developed. The equity-based model appears to raise greater amounts of capital than the reward-based model, despite most platforms being largely concerned with the reward-based model (Belleflamme, Lambert, and Schwienbacher 2013).

Lending-based model involves peer-to-peer lending (Bradford 2012). Kiva and Prosper are two prominent example platforms using this model. In this model, funders supply funds for an agreed period with the expectation of receiving their funds back, possibly with interest. Some lending-based crowdfunding platforms are exclusively interest-based. Prosper and Lending Club are two highly cited platforms that offer interest to funders on their landings. The lending-based model differs from other crowdfunding models in that only money is exchanged. The process for this model is relatively simple, but funders do risk losing their principal investment in cases where borrowers are unable to repay them. A recent study found that lending-based crowdfunding constituted around two-thirds (69 percent) of total fundraising (Agrawal, Catalini, and Goldfarb 2015).

\section{Important Elements in Crowdfunding}

Several elements play important roles in facilitating the various aspects of the crowdfunding process. This section highlights some key elements that are pertinent to crowdfunding, both as a phenomenon and as a research domain.

The role of the Internet and social media: Crowdfunding is enabled by Web 2.0 technologies (Schwienbacher and Larralde 2012; Danmayr 2014). As such, the web portals, digital interactivity tools, and e-payment systems provided by crowdfunding intermediaries form the novel bedrock for crowdfunding (Wieck, Bretschneider, and Leimeister 2013). In addition, some scholars have emphasized the significant role that social media plays in spreading awareness for a crowdfunding campaign and attracting interest, further contributing to its chances of success (Gerber and Hui 2013; Mollick 2014; Zheng et al. 2014; Colombo, Franzoni, and Rossi-Lamastra 2015). In addition, Belleflamme, Omrani, and Peitz (2015) suggest that social networks can influence the success or failure of a crowdfunding campaign in at least three ways, namely in terms of the founder's personal social networks, the in-group/cross-group social networking effect, and the use of information by crowdfunding platforms. We will now elaborate on these three influential aspects of social networking.

i. For the founder's personal social network, it has been found that social networking demographics, such as the number and type of Facebook friends/likes and Twitter followers have a recognizable effect on whom an early funder will support. Therefore, the early backers are seen as a sort of quality signal (Belleflamme, Omrani, and Peitz 2015; Colombo et al. 2015; Kromidha and Robson 2016; Mollick 2014). Similarly, Lin, Prabhala, and Viswanathan (2013) found that in peer-to-peer lending, a borrower's online friendships act as a signal of credit quality, increasing the possibility of successful funding at lower interest rates (see also Agrawal, Catalini, and Goldfarb (2015) for a discussion of how offline social relationships affect investment decisions). 
ii. Belleflamme, Omrani, and Peitz (2015) put forward the notion of "freeriders," which is those people who base their investment decisions mainly on the judgment of other backers within a social group (e. g., van Wingerden and Ryan 2011). This is evident in the skewed distribution of successful funding for projects across categories and even within the same category. In other words, some individuals are more likely to back a project if it has attracted massive interest or is close to reaching its target threshold.

iii. Some platforms enable the formation of individual groups to represent differing (special) interests (Belleflamme, Omrani, and Peitz 2015). These groups can function as a form of online community by providing mentorship, feedback, and a repository of example projects to serve as models (Hui, Greenberg, and Gerber 2014). Sharing of inside information and an exchange of insights with external agenciest leads to information asymmetry (Lin, Prabhala, and Viswanathan 2013). Information asymmetry is also a major issue in traditional financing, but it is more severe in crowdfunding. A group's dynamics and the actions of certain community members influence the overall response to a given campaign. However, friendship networks can also alleviate the problem of information asymmetry, leading to more satisfactory transaction outcomes (Lin, Prabhala, and Viswanathan 2013).

iv. Furthermore, Bellefemme et al. (2015) suggest that social networks and other technologies allow crowdfunding platforms to gather information about users' behaviors and preferences, which they can then use to recommend potential projects. This resembles how online marketplaces like Amazon and eBay recommend products.

Visual communication: The use of visual media, such as videos, technical drawings, photographs, and even interactive chat forums is very popular in crowdfunding campaigns. Indeed, this communication pattern resonates well with the visual culture of the current digital age (Fillis 2000; Klaebe and Laycock 2012). In any given crowdfunding campaign, the effective application of these communication tools plays a critical role in conveying different aspects of the necessary information. This therefore helps to bridge any gaps in the understanding between the founders and funders. In this way, understandable project objectives and value propositions help build a fan base and increase the confidence, support, and commitment of the various stakeholders.

Motivation is a force driving founders to initiate a project, and this is critical in attracting the interest of funders toward a specific project (e. g., Gerber, Hui, and Kuo 2012 February; Gerber and Hui 2013; Hui, Greenberg, and Gerber 2014; Zheng et al. 2014). Motivation is a complex cognitive construct that prompts individuals to behave or act in a particular manner. An individual's needs and wants often create a weak or strong motivational trigger for action. Founders can therefore be driven by various intrinsic and extrinsic motives (Allison et al. 2015). These motives, however, must also appeal to potential funders if a fundraising campaign is to be successful. This is where effective communication and value proposition comes in (e. g. Belleflamme, Lambert, and Schwienbacher 2014). In addition, a key motivation of founders is to bypass the scrutiny and contempt of conventional financiers (e. g., Brabham 2013; Bruton et al. 2015; Gerber et al. 2014). From the funder's perspective, Allison et al. (2015) found that prosocial funders tend to respond more positively to initiatives that present an opportunity to help others when compared to initiatives that are framed as business opportunities.

Crowdfunding is also used as a pre-ordering and marketing instrument, where the motivation for early adopters is to be among the first people to own a new product or use a new service (Gerber and Hui 2013; Gerber et al. 2014). These funders are mostly younger people. For example, van Wingerden and Ryan (2011) found that 52 percent of crowdfunders were under the age of 35. Another study by Lambert and Schwienbacher (2010) found that around 22 percent of funders do not receive any type of return on their investment, with the remaining 78 percent of crowdfunders receiving returns on their investments in the form of equity, cash, products, etc. On the other hand, Aitamurto (2011) discovered that crowdfunding for journalistic works was aimed at supporting a particular cause rather than receiving a return on their investment. Social reputation and being part of a successful effort are two major non-financial motivators for crowdfunders.

Trust and transparency: Trust is part of the core fabric of crowdfunding, because crowdfunding entails the channeling of uncollateralized funds through a non-banking intermediary to fund a specific initiative. Due to the risk of fraud, the intermediary platforms and campaigns that appear more trustworthy therefore seem to be more attractive to the public (Klaebe and Laycock 2012). Bellafemme et al. (2015) suggests that founders with successful previous campaigns are more likely to attract positive interest and receive backing for their new campaigns. For example, after Pebble managed to deliver on their massively oversubscribed smartwatch campaign of 2012, they returned to KickStarter in 2015 and raised more than US \$20.3 million for their secondgeneration smartwatch. Now in their third request, Pebble has successfully raised over US\$12.7 million in June 2016. Trust and transparency is therefore not just a key ingredient in the various stages of a project; it is also a continuous process (real-time feedback), especially in the repeat fundraising experience. Further insights into trust in crowdfunding are discussed more categorically in the following section, which deals with the ethics of crowdfunding. 


\section{Ethics of Crowdfunding}

Surprisingly, not much is said about the ethics of crowdfunding in the existing literature. We elaborate on the ethical concerns not to condemn crowdfunding or emphasize its darker side but rather to provide a wellbalanced overview of this phenomenon. To the best of our knowledge, such a balanced overview is lacking in the burgeoning crowdfunding literature. However, to provide a summary, we refer to Xu et al. (2016), who points out:

Entrepreneurs adopt crowdfunding platforms to obtain funds, expand awareness of their work, connect with others, gain approval for their work and for themselves, maintain project control [bypass the scrutiny, contempt, and costs of traditional financiers], and learn new skills ... For sponsors, receiving creative products/services (rewards) is an important motivation. In addition, helping others and being part of a community for supporting creative products also motivate them to invest in crowdfunding projects (Xu et al. 2016, p. 917).

For our purposes, these core aspects also define the difference in the ethics of crowdfunding when compared to other traditional financing options. In addition to the nature of the phenomenon and the motivational triggers, other elements differentiate and influence the ethical considerations of crowdfunding when compared to offline finance. These include the type of commitment, a pool of novice investors as funders, a lower interest rate or return on investment for funders, the role of the intermediary, transparency, the ownership structure, and a lack of expert commitment (see Agrawal, Catalini, and Goldfarb 2013; Gerber et al. 2012). Ethical issues, such as fake campaigns, loss of privacy, abuse of fund, and breach of commitment are growing concerns for crowdfunding (Snyder, Mathers, and Crooks 2016). We will now elaborate on the ethical dilemmas relevant to each of the four different crowdfunding models.

Donation-based crowdfunding: Among the four crowdfunding models, donation-based crowdfunding incurs the least risk. Funders are driven mainly by intrinsic, philanthropic, or prosocial motives when backing a donation-based crowdfunding initiative. However, there is a considerable stake in terms of moral obligations and the transparent handling of funds (e. g., Allison et al. 2015. Donors pool their money to support a cause that may be close to their hearts. It may be to help people in genuine dire need. Any misappropriation of funds could therefore have a negative effect on donors' morale. Donation-based crowdfunding is a largely unregulated activity (Hazen 2012). Some individuals and groups have therefore unfortunately abused this opportunity. It has also been criticized as a potential means for people to fund their lofty ambitions. For instance, in GoFundMe.com's travel category, almost every fourth fundraising campaign is for leisure travel purposes. While it may not be wrong for people to ask the public to fund their dream vacations, it is perturbing for them to compete against the heavily disadvantaged for sponsorship in the same category and from the same pool of funders. Some examples of these include "an elderly couple losing their home" and a "cancer-stricken teenager who needs financial help to visit a destination," perhaps as a last wish. Moreover, medical campaigns abuse the crowdfunding funds, for example, by lying about illness and creating fake campaign. On many occasions, crowdfunding websites are reluctant to intervene fraudulent because their revenues depend on the successful fundraising.

Reward-based crowdfunding: In our assessment, the reward-based crowdfunding model incurs a medium level of risk and is less complex in nature. In this model, funders are promised a non-financial reward in exchange for a monetary contribution (e. g., Allison et al. 2015; Belleflamme, Lambert, and Schwienbacher 2013). Despite the alluring simplicity of reward-based crowdfunding, the common hazards include long delays in receiving the promised product, misrepresentation, and infringement of intellectual property rights (IPRs). Hauge and Chimahusky (2016) found that over 64 percent of products (rewards) were shipped later than promised. For instance, a nascent enterprise known as Kreyos raised over \$1.5 million on IndieGoGo in November 2013 to produce its meteor smartwatch. Kreyos promised its funders a new level of experience and technology (cf., Garber 2013; Johnson 2014). However, after prolonged delays, the released product was reported to be immensely inferior. It reportedly had many flaws, including an inability to keep accurate time and an unresponsiveness to gestures. Although it was not a scam, it clearly illustrates how easy it is to mislead funders with a poorly-conceived initiative. In addition, in June 2015, BBC Technology News reported a lawsuit involving Erik Chevalier. He had raised more than $\$ 122,000$ on Kickstarter in 2012 to produce a board game called "The Doom That Came to Atlantic City." Mr. Chevalier neither produced the product nor fulfilled the orders. Instead, he canceled the project in mid-2013 citing inexperience as the reason for not fulfilling his promise. In the lawsuit, however, the Federal Trade Commission claimed that Mr. Chevalier had spent much of the raised funds on rent and personal expenses. Another case that highlights the aspect of IPRs is that of Ron Forbes. In May 2014, Mr. Forbes initiated a crowdfunding campaign on IndieGoGo to produce a feature-length version of the award-winning short film "DON'T MOVE." However, Mr. Forbes lacked the IPRs to the original film, and had no permission to use the 
copyrighted materials. The campaign was fortunately halted and any fraud prevented. Founders tend to overpromise in their campaigns, and funders do not always have sufficient experience and capability to perform due diligence before funding a project. The above discussion highlights the serious ethical issues surrounding reward-based crowdfunding.

Equity-based crowdfunding: Common ethical issues surrounding equity-based crowdfunding include the pricing of equity, moral obligations, issues with unskilled investors, problems with recapitalization, realignment, and a danger of creating a new economic bubble. Belleflamme, Lambert, and Schwienbacher (2013) argue that crowdfunding allows entrepreneurs to practice behavior-based price discrimination. A profit-oriented organization may be prone to focusing too much on its profits, leading them to compromise the quality of its offerings. Entrepreneurs set perks in a campaign at a phase when market estimations are lacking (De Buysere et al. 2012). The equity-based crowdfunding model combines investment risk with unsophisticated investors (Bradford 2012). This model, therefore, attracts a large pool of funders with divergent interests and experiences from varying backgrounds. Consequently, it is very challenging for a new, resource-constrained venture to manage (De Buysere et al. 2012). In contrast, experienced investors provide more than finance to new ventures, and they are often prepared for follow-on investment rounds. Griffin (2013) argues that the legislators and advocates of crowdfunding have equally failed to perceive the adverse consequences of equity crowdfunding being exempted from registration with the U.S. Securities and Exchange Commission (SEC). Moreover, some analysts believe that allowing crowdfunding platforms to offer equity will potentially open the door for the next financial bubble to enter the securities market. A Las Vegas-based company - Ascenergy - has raised approximately \$5 million in 2015 as fraudulent equity through crowdfunding from 90 national and international investors. Ascenergy shifted the most of the amount to its different entities. SEC was able to halt this ill endeavor at a point to prevent any further damage. Hence, including antifraud provisions in crowdfunding legislation is essential (Bradford 2012) to mitigate the risks associated with equity-based crowdfunding. Some scholars also suggest creating an insurance system that will encourage the identification of fraudulent and overpriced offerings (Li 2013; Palmiter 2012). However, various regulatory agencies are working to protect specially the funders' rights.

Lending-based crowdfunding: Lending-based crowdfunding seems a simple and straightforward model, but broken promises is a potential ethical concern. In this model, funders finance an initiative in the expectation of receiving the money back, possibly with interest. The associated risk is therefore of a low-to-medium level. One concrete example is the peer-to-peer lending platform Kiva.org, which boasts a 97.2 percent repayment rate. This is very impressive for uncollateralized loans. Moss et al. (2015), however, warn that "the lack of credible, reliable information about borrowers poses serious challenges to lenders" (p. 28). Funders of this category have limited experience and knowledge about the project they fund as such they need to invest with a high risk of return.

The moral hazard associated with lending-based crowdfunding is multifaceted. In fact, something that is often not sufficiently appraised by both founders and funders is the level of success a venture needs before it can repay the raised funds, as well as the often-high interest rates on the capital (Moss et al., 2015). This can force even well-intentioned enterprises to either collapse or default on their payments. From an entrepreneurial perspective, lending-based crowdfunding has the potential to make honest entrepreneurs toil in vain, because even if they manage to repay the loans as promised, they may be left with little or no funds to continue their businesses. Therefore, even when the capital is repaid to funders, a failed enterprise may not fulfill the main goals and expectations of either the founder or funders. On the other hand, unscrupulous individuals can intentionally bankrupt their enterprises and default on their loans, robbing the funders of their capital and depriving the greater society of the benefits. Recently, Lending Club - the biggest US lending-based crowdfunding platform - has experienced employee fraud and it chief executive resigned. That said, it should be noted that such behavior is not exclusive to crowdfunded loans.

\section{Discussion and Conclusion}

This paper has explored crowdfunding as a recent, promising phenomenon. We have explained the crowdfunding phenomenon and its characteristics, typology, key elements, and the key ethical issues. The implications of this research and future research avenues are presented below.

\section{Implications for Theory}

Crowdfunding differs from other sources of entrepreneurial finance; therefore, further exploration of how its characteristics differ from the alternatives is still warranted. Funders can generally only rely upon the information provided by the founders during a crowdfunding campaign, so performing a reality check is difficult 
due to insufficient information. Hence, information symmetry is a key concern in crowdfunding. Although the main aim of a crowdfunding campaign is to raise funds, it also helps entrepreneurs to test, promote, and market their products, as well as gain a better understanding of their consumers and innovate accordingly (Stanko and Henard 2016). To attract a large number of funders, entrepreneurs should build a network through social media. Studies have found that the early backers of a fundraising campaign are predominantly friends and family members. Entrepreneurs need to establish the right crowd-based community as per their financial and operational needs. The roles and functions of intermediary crowdfunding platforms are mostly known for their knowledge sharing, but some studies have found that many platforms conceal information or even reveal distorted information (Mollick 2014). In addition, many founders with unfeasible projects can raise funds from naive funders who exhibit a herding behavior.

As the crowdfunding discipline advances from its nascent to mature stage, building theories about the various dimensions of crowdfunding is important. This includes exploring the milieu within which founders exist, how they groom their funders, and which factors lead to success or failure, because this will accelerate the process of theory building for crowdfunding. Academics lack a coherent theory for the crowdfunding phenomenon. The theory of finance involves studying ways in which businesses and individuals raise funds and allocate them to projects by considering the associated risk. Crowdfunding functions in a loosely designed environment. The risks associated with crowdfunding, therefore, differ from those of the traditional alternatives. Expanding the theory of finance to include crowdfunding is an essential endeavor. Social exchange theory postulates that human relationships are formed by applications of a subjective cost-benefit analysis. The role of trust, commitment, innovative products, tangible and intangible outcomes, a sense of belonging, and the cognitive process funders use during crowdfunding has been limitedly discussed in the literature (Liu et al. 2016). Social media also plays a key role in crowdfunding, so using social identity theory is appropriate for exploring crowdfunding (Ahlers et al. 2015; Kromidha and Robson 2016). Funders who identify themselves in a social network have a greater potential to fund a project in that social network. How social identity theory and signaling theory differ between online and traditional entrepreneurship environments is essential to understanding the various facets of crowdfunding (Kromidha and Robson 2016). Crowdfunding can take place in formal and informal institutions, with different institutions having differing patterns of effect (Kshetri 2015), so institutional theory can be used to explore the various agencies involved with crowdfunding. Signaling theory may also give us a deeper understanding of how funders, founders, and other stakeholders operate. Therefore, crowdfunding can be explored from various theoretical lenses.

\section{Implications for Practitioners}

This article presents several implications for practitioners. Although we hinted at the general success of crowdfunding, it is a challenge to launch a crowdfunding project. Legislation is not yet well established, and there are significant differences in the laws of various regions. We urge governments and other agencies to harmonize legislation around the world. Many crowdfunding platforms and projects operate in a realm with few checks and balances. Fundraising through crowdfunding is often a tempting option for early-stage startups, but many of these fail to deliver on their promises. Moreover, fraud committed by unscrupulous founders also raises ethical concerns. The lack of established legislation and the potential for unethical behavior from various stakeholders suggest that developing and implementing effective legislative mechanisms is essential. Funders will then be more inclined to participate in crowdfunding activities. Crowdfunding differs significantly from other funding mechanisms, such as venture capital, seed funding and bank loans, so it should be considered as an entirely different kind of funding. This article reinforces the importance of crowdfunding as a source of funding for early-stage start-ups, and it expects to encourage crowdfunding stakeholders to explore and integrate new insights. Sources of funding are decreasing, so crowdfunding should be considered as essential alternative source for various initiatives.

\section{Future Research Avenues}

This article indicates a range of issues that need to be articulated in order to accurately outline the crowdfunding discipline. The definition proposed in this article is very comprehensive, so future studies could explore the various dimensions of the crowdfunding concept by considering this definition. For example, crowdfunding platforms could be considered and compared with other online platforms, such as online marketplaces. Future studies are needed to thoroughly explore crowdfunding and its various dimensions, because it is still not clear why some crowdfunding projects are very successful while others fail. In many cases, founders offer funders several perks for funding a campaign, but it is not known how these perks lead to the success or failure of a 
crowdfunding initiative. Therefore, exploring the function of these perks could be an interesting avenue for future research.

The antecedents and consequences of crowdfunding projects must be carefully analyzed from various viewpoints, such as those of individual founders and funders, intermediary platforms, and policy makers. A deep understanding of all the related variables is essential. Therefore, future researchers should examine how contextual variables influence different crowdfunding campaigns. Ethical transgressions could also prevent crowdfunding from maturing as an industry. Hence, ethical issues related to the different types of crowdfunding warrant further thoughtful analysis. Ultimately, uniform, well-rounded legislation will be needed, so legal scholars could contribute to the relevant authorities in this endeavor.

Future research may also look at how crowdfunding platforms incorporate early-warning systems for ethical violations, how legislation may curb ethical transgressions, and how funders could be assured they will receive a return from the funder. These issues underscore the importance of studying crowdfunding and its associated ethics. We hope this article will inspire scholars to pursue research into these and other crucial issues.

\section{Acknowledgement}

Mokter Hossain is grateful to the Finnish Cultural Foundation for financial support. Both authors contributed equally and authors' names have been placed in alphabetical order. A previous version of the paper has been presented in the AoM conference 2016. An initial version of the paper was submitted by Mokter Hossain as assignment for the summer school called EDEN Doctoral Seminar on Entrepreneurship: Current Themes and Research in Entrepreneurship, Helsinki, 5-8 May 2014.

\section{Funding}

Suomen Kulttuurirahasto

\section{References}

Agrawal, A. K., C. Catalini, and A. Coldfarb. 2013. “Some simple economics of crowdfunding (No. w19133). National Bureau of Economic Research.".

Agrawal, A., C. Catalini, and A Coldfarb. 2015. “Crowdfunding: Ceography, Social Networks, and the Timing of Investment Decisions." Journal of Economics \& Management Strategy 24 (2): 253-274.

Ahlers, G. K., D. Cumming, C. Cünther, and D. Schweizer. 2015. “Signaling in Equity Crowdfunding." Entrepreneurship Theory and Practice 39 (4): 955-980.

Aitamurto, T. 2011. "The Impact of Crowdfunding on Journalism: Case Study of Spot. Us, a Platform for Community-Funded Reporting." Journalism Practice 5 (4): 429-445.

Allison, T. H., B. C. Davis, J. C. Short, and J. W. Webb. 2015. “Crowdfunding in a Prosocial Microlending Environment: Examining the Role of Intrinsic versus Extrinsic Cues." Entrepreneurship Theory and Practice 39 (1): 53-73.

Assenova, V., J. Best, M. Cagney, D. Ellenoff, K. Karas, J. Moon, and O. Sorenson. 2016. "The Present and Future of Crowdfunding." California Management Review 58 (2): 125-135.

Bannerman, S. 2013. “Crowdfunding Culture." Journal of Mobile Culture 7: 1.

BBC. 2015, http://www.bbc.com/news/technology-33108064.

Belleflamme, P., T. Lambert, and A. Schwienbacher. 2010, June. “Crowdfunding: An industrial organization perspective." In Prepared for the workshop Digital Business Models: Understanding Strategies' 25-26. held in Paris on June.

Belleflamme, P., T. Lambert, and A. Schwienbacher. 2013. “Individual Crowdfunding Practices." Venture Capital: an International Journal of Entrepreneurial Finance 15 (4): 313-333.

Belleflamme, P., T. Lambert, and A. Schwienbacher. 2014. “Crowdfunding: Tapping the Right Crowd.” Journal of Business Venturing 29 (5): 585-609.

Belleflamme, P., N. Omrani, and M. Peitz. 2015. "The Economics of Crowdfunding Platforms." Information Economics and Policy 33: 11-28.

Belt, B., C. Brummer, and D. Corfine. 2012. Crowdfunding: Maximizing the Promise and Minimizing the Peril. Washington, DC: Milken Institute.

Blanchard, A., and E. Sabuncu. 2016. "Recommendations of the Ethics Committee of the French Research Institute for Development on Crowdfunding: Potential and Limits." Natures Sciences Societies 24 (2): 154-159.

Brabham, D. C. 2013. Crowdsourcing. Cambirdge, Massachusetts and London, England: MIT Press.

Bradford, C. S. 2012. "Crowdfunding and the Federal Securities Laws." Columbia Business Law Review (1).

Burtch, G., A. Ghose, and S. Wattal. 2013. "An Empirical Examination of the Antecedents and Consequences of Contribution Patterns in Crowd-Funded Markets." Information Systems Research 24 (3): 499-519.

Burtch, G., A. Chose, and S. Wattal. 2015. "The Hidden Cost of Accommodating Crowdfunder Privacy Preferences: A Randomized Field Experiment." Management Science 61 (5): 949-962. 
Bruton, G., S. Khavul, D. Siegel, and M. Wright. 2015. "New Financial Alternatives in Seeding Entrepreneurship: Microfinance, Crowdfunding, and Peer-to-Peer Innovations." Entrepreneurship Theory and Practice 39 (1): 9-26.

Colombo, M. C., C. Franzoni, and C. Rossi-Lamastra. 2015. “Internal Social Capital and the Attraction of Early Contributions in Crowdfunding." Entrepreneurship Theory and Practice 39 (1): 75-100.

Cowling, M., W. Liu, A. Ledger, and N. Zhang. 2015. “What Really Happens to Small and Medium-Sized Enterprises in a Clobal Economic Recession? UK Evidence on Sales and Job Dynamics." International Small Business Journal 33 (5): 488-513.

Crowdsourcing, L. L. C.. 2012. "Crowdfunding industry report: market trends, composition and crowdfunding platforms.", http://www.crowdsourcing.org/document/crowdfunding-industry-report-abridged-version-market-trends-compositionandcrowdfundingplatforms/14277.

Crowdfunding Industry Report. 2015. “2015CF-Crowdfunding Industry Report.”, http://ncfacanada.org/2015-massolution-report-releasedcrowdfunding-market-grows-167-in-2014-crowdfunding-platforms-raise-16-2-billion/.

Danmayr, F. 2014. "Web 2.0 and Crowdfunding Platforms." In Archetypes of Crowdfunding Platforms., 7-48. Wiesbaden: Springer Fachmedien.

De Buysere, K., O. Gajda, R. Kleverlaan, D. Marom, and M. Klaes. 2012. “A Framework for European Crowdfunding.” European Crowdfunding $\operatorname{Network}(E C N)$, www.europecrowdfunding.org/european_crowdfunding_framework.

Fillis, I. 2000. "Being Creative at the Marketing/Entrepreneurship Interface: Lessons from the Art Industry." Journal of Research in Marketing and Entrepreneurship 2 (2): 125-137.

Fraser, S., S. K. Bhaumik, and M. Wright. 2015. "What Do We Know about Entrepreneurial Finance and Its Relationship with Growth?" International Small Business Journal 33 (1): 70-88.

Garber, L. 2013. "Cestural Technology: Moving Interfaces in a New Direction [Technology News]." Computer 46 (10): 22-25.

Griffin, Z. J. 2013. “Crowdfunding: fleecing the American masses." Case W. Res. JL Tech. \& Internet 375. 4: 375.

Cerber, E. M., J. S. Hui, and P. Y. Kuo. 2012 February. “Crowdfunding: Why people are motivated to post and fund projects on crowdfunding platforms. In Proceedings of the International Workshop on Design, Influence, and Social Technologies: Techniques, Impacts and Ethics.".

Gerber, E. M., and J. Hui. 2013. “Crowdfunding: Motivations and Deterrents for Participation." ACM Transactions on Computer-Human Interaction 20 (6): 1-32.

Cerber, E. M., M. Muller, R. Wash, L. C. Irani, A. Williams, and E. F. Churchill. 2014. "ACM Crowdfunding: An Emerging Field of Research." In." Proceedings of the extended abstracts of the 32nd annual ACM conference on Human factors in computing systems 1093-1098.

Harrison, R. 2013. “Crowdfunding and the Revitalisation of the Early Stage Risk Capital Market: Catalyst or Chimera?” Venture Capital: An International Journal of Entrepreneurial Finance 15 (4): 283-287.

Harrington, K. 2014. “Cashing in on Crowdfunding.", http://www.forbes.com/sites/kevinharrington/2014/02/07/cashing-in-oncrowdfunding/\#1ea514ec34fc

Hauge, J. A., and S. Chimahusky. 2016. “Are Promises Meaningless in an Uncertain Crowdfunding Environment?” Economic Inquiry 54 (3): $1621-1630$.

Hazen, T. L. 2012. “Crowdfunding or Fraudfunding? Social Networks and the Securities Laws - Why the Specially Tailored Exemption Must Be Conditioned on Meaningful Disclosure." North Carolina Law Review 90: 2015.

Hemer, J. 2011. Karlsruhe: Fraunhofer ISI A Snapshot on Crowdfunding (No. R2/2011)Working papers firms and region.

Heminway, J. M. 2014. “How Congress Killed Investment Crowdfunding: A Tale of Political Pressure, Hasty Decisions, and Inexpert Judgments that Begs for A Happy Ending." Kentucky Law Journal 102: 2013-2014.

Heminway, J. M., and S. R. Hoffman. 2010. "Proceed at Your Peril: Crowdfunding and the Securities Act of 1933." Tennessee Law Reviews 78: 879.

Hollas, J. 2013. “Is Crowdfunding Now a Threat to Traditional Finance?” Corporate Finance Review 18 (1): 27.

Hossain, M. 2015. "Crowdsourcing in Business and Management Disciplines: An Integrative Literature Review." Journal of Clobal Entrepreneurship Research 5 (1): 1-19.

Howe, J. 2006. “The Rise of Crowdsourcing." Wired Magazine 14 (6): 1-4.

Hui, J. S., M. D. Greenberg, and E. M. Cerber. 2014. "Understanding the Role of Community in Crowdfunding Work.." In Proceedings of the 17th ACM Conference on Computer Supported Cooperative Work and Social Computing., 62-74. ACM.

Ingram, C., and R. Teigland. 2013. "Crowdfunding among IT entrepreneurs in Sweden: A qualitative study of the funding ecosystem and ICT entrepreneurs' adoption of crowdfunding Available at SSRN 2289134.", https://papers.ssrn.com/sol3/papers.cfm?abstract_id=2289134.

James, T. C. 2013. "Far from the Maddening Crowd: Does the JOBS Act Provide Meaningful Redress to Small Investors for Securities Fraud in Connection with Crowdfunding Offerings." BCL Rev 54: 1767.

Johnson, K. M. 2014. “Literature Review: An Investigation into the Usefulness of the Smart Watch Interface for University Students and the Types of Data they would Require.", http://img1.wikia.nocookie.net/_cb20140801120101/mobile-computing-prediction/images/c/c7/Literature_Review_KM].pdf.

Jones, M. V., N. Coviello, and Y. K. Tang. 2011. “International Entrepreneurship Research (1989-2009): A Domain Ontology and Thematic Analysis." Journal of Business Venturing 26 (6): 632-659.

Keupp, M. M., and O. Gassmann. 2009. "The past and the Future of International Entrepreneurship: A Review and Suggestions for Developing the Field." Journal of Management 35 (3): 600-633.

Klaebe, H. G., and R. Laycock. 2012 How to Work the Crowd: A Snapshot of Barriers and Motivations to Crowdfunding Australia Council for the Arts, Sydney, NSW.

Kromidha, E., and P. Robson. 2016 Social Identity and Signalling Success Factors in Online Crowdfunding 1-25. Entrepreneurship \& Regional Development.

Kshetri, N. 2015. "Success of Crowd-Based Online Technology in Fundraising: an Institutional Perspective." Journal of International Management 21 (2): 100-116.

Lebraty, J. F., and K. Lobre-Lebraty. 2013. Crowdsourcing: One Step Beyond. John Wiley \& Sons. 
Li, T. Q. 2013. “Fraud in Crowdfunding and Antifraud Insurance. Available at SSRN 2273263.”, https://papers.ssrn.com/sol3/papers.cfm?abstract_id=2273263.

Lin, M., N. R. Prabhala, and S. Viswanathan. 2013. "Judging Borrowers by the Company They Keep: Friendship Networks and Information Asymmetry in Online Peer-To-Peer Lending." Management Science 59 (1): 17-35.

Liu, Z., Q. Min, Q. Zhai, and R. Smyth. 2016. "Self-Disclosure in Chinese Micro-Blogging: A Social Exchange Theory Perspective." Information 8 Management 53 (1): 53-63.

Macht, S. A., and J. Weatherston. 2014. “The Benefits of Online Crowdfunding for Fund-Seeking Business Ventures." Strategic Change 23 (1-2): $1-14$.

Marom, D., A. Robb, and O. Sade. 2015. “Cender Dynamics in Crowdfunding (Kickstarter): Evidence on Entrepreneurs, Investors, Deals and Taste-Based Discrimination. Investors, Deals and Taste-Based Discrimination. Investors, Deals and Taste-Based Discrimination (December 6, 2015)".

McMillan Web-Dictionary. 2016 http://www.macmillandictionary.com(retrieved on 15th of January, 2012).

Mollick, E. 2014. “The Dynamics of Crowdfunding: an Exploratory Study.” Journal of Business Venturing 29 (1):1-16.

Mollick, E. R., and R. Nanda. 2016. "Wisdom or Madness? Comparing Crowds with Expert Evaluation in Funding the Arts." Management Science 62 (6): 1533-1553.

Moss, T. W., D. O. Neubaum, and M. Meyskens. 2015. “The effect of virtuous and entrepreneurial orientations on microfinance lending and repayment: A signaling theory perspective." Entrepreneurship Theory and Practice 39 (31): 27-52.

Oxford Dictionary. 2014, https://en.oxforddictionaries.com/definition/us/crowdfunding.

Palmiter, A. R. 2012. "Pricing Disclosure: Crowdfunding's Curious Conundrum.”, https://papers.ssrn.com/sol3/papers.cfm?abstract_id=2241833.

Pichler, F., and I. Tezza. 2016. “Crowdfunding as a New Phenomenon: Origins, Features and Literature Review.” In Crowdfunding for SMEs., 5-43. Palgrave Macmillan UK.

Rechtman, Y., and S. O'Callaghan. 2014. “Understanding the Basics of Crowdfunding." The CPA Journal 84 (11): 30-33.

Rubinton, B.J. 2011. “Crowdfunding: disintermediated investment banking. Available at SSRN 1807204.", https://papers.ssrn.com/sol3/papers.cfm?abstract_id=1807204.

Schwienbacher, A., and B. Larralde. 2010. “Crowdfunding of small entrepreneurial ventures. Handbook of entrepreneurial finance, Oxford University Press".

Schwartz, A. A. 2013. “Crowdfunding Securities." Notre Dame Law Review 88: 1457.

Schwienbacher, A., and B. Larralde. 2012. "Crowdfunding of Small Entrepreneurial Ventures." In Oxford Handbook of Entrepreneurial Finance., edited by D. Cumming, 369-390. New York: Oxford University Press.

Snyder, J., A. Mathers, and V. A. Crooks. 2016. "Fund My Treatment!: A Call for Ethics-Focused Social Science Research into the Use of Crowdfunding for Medical Care." Social Science \& Medicine 169: 27-30.

Stanko, M. A., and D. H. Henard. 2016. “How Crowdfunding Influences Innovation.” MIT Sloan Management Review 57 (3): 15-17.

Steinberg, S., R. DeMaria, and J. Kimmich. 2012. "The crowdfunding bible. How to raise money for any startup, video game or project. oO: READ. ME." www.crowdfundingguides.com/The\%20Crowdfunding\%20Bible.pdfzuletzt geprüft am, 12, 2015.

van Wingerden, R. P., and J. Ryan. 2011. “Fighting for Funds: An Exploratory Study into the Field of Crowdfunding.", http://www.lunduniversity.lu.se/lup/publication/1982630.

Wieck, E., U. Bretschneider, and J. M. Leimeister. 2013. "Funding from the Crowd: An Internet-Based Crowdfunding Platform to Support Business Set-Ups from Universities." International Journal of Cooperative Information Systems 22 (3): 1-21.

Xiang, D., A. C. Worthington, and H. Higgs. 2014. “Discouraged Finance Seekers: an Analysis of Australian Small and Medium-Sized Enterprises." International Small Business Journal 33 (1): 70-88.

Xu, B., H. Zheng, Y. Xu, and T. Wang. 2016. "Configurational Paths to Sponsor Satisfaction in Crowdfunding." Journal of Business Research 69 (2): 915-927.

Younkin, P., and K. Kashkooli. 2016. “What Problems Does Crowdfunding Solve?” California Management Review 58 (2): $20-43$.

Wojciechowski, Adam. 2009. “Models of Charity Donations and Project Funding in Social Networks." Lecture Notes in Computer Science 5872 454-463.

Wicks, M. 2013 Crowdfunding - An IntroductionVictoriaBlue Beetle Books.

Zhang, J., and P. Liu. 2012. "Rational herding in microloan markets." HManagement Science 58 (5): 892-912.

Zheng, H., D. Li, J. Wu, and Y. Xu. 2014. "The Role of Multidimensional Social Capital in Crowdfunding: A Comparative Study in China and US." Information \& Management 51 (4): 488-496. 